\title{
Ghrelin receptor antagonism attenuates cocaine- and amphetamine-induced locomotor stimulation, accumbal dopamine release, and conditioned place preference
}

\author{
Elisabet Jerlhag • Emil Egecioglu • \\ Suzanne L. Dickson • Jörgen A. Engel
}

Received: 22 December 2009 / Accepted: 3 June 2010 /Published online: 19 June 2010

(C) The Author(s) 2010. This article is published with open access at Springerlink.com

\begin{abstract}
Introduction Recently we demonstrated that genetic or pharmacological suppression of the central ghrelin signaling system, involving the growth hormone secretagogue receptor 1A (GHS-R1A), lead to a reduced reward profile from alcohol. As the target circuits for ghrelin in the brain include a mesolimbic reward pathway that is intimately associated with reward-seeking behaviour, we sought to determine whether the central ghrelin signaling system is required for reward from drugs of abuse other than alcohol, namely cocaine or amphetamine.

Results We found that amphetamine-as well as cocaineinduced locomotor stimulation and accumbal dopamine release were reduced in mice treated with a GHS-R1A antagonist. Moreover, the ability of these drugs to condition a place preference was also attenuated by the GHS-R1A antagonist.

Conclusions Thus GHS-R1A appears to be required not only for alcohol-induced reward, but also for reward induced by psychostimulant drugs. Our data suggest that the central ghrelin signaling system constitutes a novel potential target for treatment of addictive behaviours such as drug dependence.
\end{abstract}

E. Jerlhag $(\bowtie) \cdot$ J. A. Engel

Section for Pharmacology,

Institute of Neuroscience and Physiology,

The Sahlgrenska Academy at the University of Gothenburg,

SE-405 30 Gothenburg, Sweden

e-mail: elisabet.jerlhag@pharm.gu.se

E. Egecioglu $\cdot$ S. L. Dickson

Section for Physiology/Endocrinology,

Institute of Neuroscience and Physiology,

The Sahlgrenska Academy at the University of Gothenburg,

SE-405 30 Gothenburg, Sweden
Keywords Psychostimulant drugs · Ghrelin .

Reinforcement · Accumbens · VTA

\section{Introduction}

Since its discovery in 1999 (Kojima et al. 1999), the stomach-derived hormone ghrelin has been studied extensively in the context of appetite and energy balance regulation (Nogueiras et al. 2006). It seems clear that ghrelin exerts its orexigenic and pro-obesity effects by interacting with discrete hypothalamic cell groups that include leptin-responsive circuits in the arcuate nucleus, such as the neuropeptide $\mathrm{Y}$ cell group (Dickson and Luckman 1997; Hewson et al. 2002; Nogueiras et al. 2006). Recently, however, we and others have reported that ghrelin also activates key CNS pathways involved in reward, that include the mesolimbic dopamine system (Abizaid et al. 2006; Jerlhag et al. 2006) and, more specifically, the cholinergic-dopaminergic reward link (Jerlhag et al. 2007, 2008). By this route, ghrelin may increase the incentive value of both natural and artificial rewards and hence, increase reward-seeking behavior.

The emerging neurobiology of central ghrelin signaling system indicates that it may serve as a common denominator to enhance search for rewards such as drugs of abuse and rewarding foods. This is evidenced, in part, by human function imaging studies in which ghrelin was shown to alter the brain response to visual food cues, most markedly in the ventral striatum, an area also activated by psychostimulant drugs (see e.g. Wise and Bozarth 1987; Malik et al. 2008). In rodents, ghrelin has been shown to increase foraging for food (Keen-Rhinehart and Bartness 2004), to 
enhance cocaine-induced locomotor stimulation, to condition a place preference for cocaine, and to induce cocaineseeking behaviors (Wellman et al. 2005; Davis et al. 2007; Tessari et al. 2007). Recently, we demonstrated that central ghrelin signaling system is required for alcohol reward; we found that the ability of alcohol to increase locomotor activity, to induce accumbal dopamine release, and to condition a place preference were abolished in ghrelin receptor growth hormone secretagogue receptor 1A (GHS-R1A) in knockout mice and also in mice treated with two different GHS-R1A antagonists (Jerlhag et al. 2009). In the present study, such tests were also used to determine whether the central ghrelin signaling system is required for the rewarding properties of cocaine and amphetamine in mice treated peripherally with a GHSR1A antagonist.

\section{Materials and methods}

\section{Animals}

Adult post-pubertal age-matched male NMRI mice (812 weeks old and 25-40 g body weight; B\&K Universal AB; Sollentuna, Sweden) were used for studies of locomotor activity, dopamine release, and conditioned place preference (CPP) testing, as such studies are well documented in this strain (Jerlhag et al. 2006, 2007, 2008; Jerlhag 2008). All mice were maintained at $20^{\circ} \mathrm{C}$ with $50 \%$ humidity and a 12/12 h light/dark cycle (lights on at 7 a.m.). Tap water and food (Normal chow; Harlan Teklad; Norfolk, England) were supplied ad libitum, except during the experimental setups. Studies were approved by the Ethics Committee for Animal Experiments in Gothenburg, Sweden

\section{Drugs}

Dex-amphetamine sulphase (RBI; Natick, USA) was dissolved in vehicle ( $0.9 \%$ sodium chloride solution) and was administered intraperitoneally (i.p.) at a dose of $2 \mathrm{mg} / \mathrm{kg}$ $10 \mathrm{~min}$ prior to initiation of the experiment. Cocaine (Sigma; St Louise, USA) was dissolved in the vehicle ( $0.9 \%$ sodium chloride solution) and was administered i.p. at a dose of $10 \mathrm{mg} / \mathrm{kg} 10 \mathrm{~min}$ prior to the initiation of the experiment. Similar doses have been used previously to induce an activation of the mesolimbic dopamine system, as measured by locomotor activity and accumbal dopamine release in rats (Wise and Bozarth 1987). The selected dose of JMV2959 (synthesized at the Institut des Biomolécules Max Mousseron, UMR5247, CNRS, Montpellier 1 and 2 Universities, France), a GHS-R1A antagonist, was determined previously (6 mg/kg, i.p.) (Jerlhag et al. 2009). This dose was used in all studies and was always administered 10 min prior to drug exposure. Indeed, it has been established that this compound, when administered peripherally, is a GHS-R1A antagonist and suppresses food intake induced by ghrelin or by the GHS-R1A agonist, hexarelin (Moulin et al. 2007; Salomé et al. 2009). Previous radioligand binding studies have also established that JMV2959 is a GHS-R1A antagonist (Moulin et al. 2007). JMV2959 was dissolved in vehicle ( $0.9 \%$ sodium chloride solution). All drug challenges were part of a balanced design with regard to both the treatment order and the number of subjects per treatment. For all drug challenges, 0.9\% sodium chloride solution was used as vehicle.

\section{Locomotor activity experiments}

Amphetamine- or cocaine-induced locomotor stimulation was measured as most drugs of abuse cause locomotor stimulation, an effect mediated, at least in part, by their ability to enhance the extracellular concentration of accumbal dopamine (Engel et al. 1988, 1992). Such parameters have been suggested to be homologous effects evolving from a common mechanism involving the dopaminergic reward system, implying that these parameters reflect reward induced by drugs of abuse (Engel et al. 1988; Imperato and Di Chiara 1986; Wise and Bozarth 1987). It should, however, be emphasized that several other neurostransmitter systems may mediate drug-induced locomotor stimulation (Engel et al. 1992). Whereas CPP-testing demonstrates drug-induced reward more directly, locomotor stimulation provides an indirect, yet supportive measure. Locomotor activity was recorded as described previously (Jerlhag et al. 2006).

Locomotor activity was registered in eight soundattenuated, ventilated, and dimly lit locomotor boxes $(420 \times 420 \times 200 \mathrm{~mm}$, Kungsbacka mät- och reglerteknik $\mathrm{AB}$, Fjärås, Sweden). Five by five rows of photocell beams, at the floor level of the box, creating photocell detection allowed a computer-based system to register the activity of the mice. Locomotor activity was defined as the accumulated number of new photocell beams interrupted during a 60-min period.

Mice were allowed to habituate to the locomotor activity box $1 \mathrm{~h}$ prior to drug challenge. In separate experiments, the effects of the i.p.-administered JMV2959 $(6 \mathrm{mg} / \mathrm{kg})$ on amphetamine (2 mg/kg, i.p.) or cocaine $(10 \mathrm{mg} / \mathrm{kg}$, i.p.) locomotor stimulation was investigated in mice. All mice received drug treatment only twice (GHS-R1A antagonist/ vehicle and psychostimulant drug/vehicle). Neither water nor food was available to the mice during the locomotor experiments. The activity registration started $5 \mathrm{~min}$ after the last injection and was subsequently measured for a $60-\mathrm{min}$ period. 
In vivo microdialysis and dopamine release measurements

For measurements of extracellular dopamine levels (that reflect dopamine release), mice were implanted unilaterally with a microdialysis probe positioned in the nucleus accumbens (NAcc). The surgery was performed as described thoroughly elsewhere (Jerlhag et al. 2006). In brief, the mice were anesthetized with isofluran (Isofluran Baxter; Univentor 400 Anaesthesia Unit, Univentor Ltd., Zejtun, Malta), placed in a stereotaxic frame (David Kopf Instruments; Tujunga, CA, USA), and kept on a heating pad to prevent hypothermia. The scull bone was exposed and one hole for the probe and one for the anchoring screw were drilled. The probe was randomly alternated to either the left or right side. The coordinates for NAcc were $1.5 \mathrm{~mm}$ anterior to the bregma, \pm 0.7 lateral to the midline, and $4.7 \mathrm{~mm}$ below the surface of the brain surface (Franklin and Paxinos 1996). The exposed tip of the dialysis membrane $(20,000 \mathrm{kDa}$ cut off with an od/id of $310 / 220 \mu \mathrm{m}$, HOSPAL, Gambro, Lund, Sweden) of the probe was $1 \mathrm{~mm}$. All probes were surgically implanted 2 days prior to the experiment. After surgery, the mice were kept in individual cages (Macrolon III).

In separate experiments, the effects of JMV2959 (i.p.) on amphetamine- or cocaine-induced accumbal dopamine release using microdialysis in freely moving mice was investigated. On the day of the experiment, the probe was connected to a microperfusion pump (U-864 Syringe Pump; AgnThós $\mathrm{AB}$ ) and perfused with Ringer solution at a rate of $1.5 \mu \mathrm{l} /$ minute. After $1 \mathrm{~h}$ of habituation to the microdialysis set-up, perfusion samples were collected every $20 \mathrm{~min}$. The baseline dopamine level was defined as the average of three consecutive samples before the first drug/vehicle challenge, and the increase in accumbal dopamine was calculated as the percent increase from baseline. After the baseline samples, mice were injected with JMV2959 (i.p.), which was followed by an amphetamine or cocaine (i.p.) injection in separate experiments. The dopamine levels in the dialysates were determined by HPLC with electrochemical detection. A pump (Gyncotec P580A; Kovalent AB; V. Frölunda, Sweden), an ion exchange column $(2.0 \times 100 \mathrm{~mm}$, Prodigy $3 \mu \mathrm{m} \mathrm{SA}$; Skandinaviska GeneTec AB; Kungsbacka, Sweden), and a detector (Antec Decade; Antec Leyden; Zoeterwoude, The Netherlands) equipped with a VT-03 flow cell (Antec Leyden) were used. The mobile phase (pH 5.6), consisting of sulfonic acid $10 \mathrm{mM}$, citric acid $200 \mathrm{mM}$, sodium citrate $200 \mathrm{mM}, 10 \%$ EDTA, 30\% $\mathrm{MeOH}$, was vacuum filtered using a $0.2-\mu \mathrm{m}$ membrane filter (GH Polypro; PALL Gelman Laboratory; Lund, Sweden). The mobile phase was delivered at a flow rate of $0.2 \mathrm{ml} / \mathrm{min}$ passing a degasser (Kovalent $\mathrm{AB}$ ), and the analyte was oxidized at $+0.4 \mathrm{~V}$ (Blomqvist et al. 1993; Westerink 1995).
After the completion of the microdialysis experiments, the locations of the probe were verified (Jerlhag et al. 2006). Only mice with probe placement in the NAcc were included in the statistical analysis.

Verification of probe placement

After the microdialysis experiments were completed, the location of the probe was verified. The mice were decapitated, probes were perfused with pontamine sky blue 6BX to facilitate probe localization, and the brains were mounted on a vibroslice device (752 M Vibroslice; Campden Instruments Ltd., Loughborough, UK). The brains were cut in $50-\mu \mathrm{m}$ sections, and the location of the probe was determined by gross observation using light microscopy. The exact position (some correct and some misplaced) of the probe and/or guide cannula/e was verified (Franklin and Paxinos 1996).

\section{Conditioned place preference}

To further evaluate the effects of GHS-R1A on the rewarding effects of amphetamine or cocaine, CPP tests were performed in mice. A two-chambered CPP apparatus, with distinct visual and tactile cues, was used (SanchisSegura and Spanagel 2006; Jerlhag 2008; Jerlhag et al. 2009). One compartment was defined by black- and white-striped walls and by a dark laminated floor, whereas the other had a white unlaminated floor and walls of wooden texture. Compartments were illuminated by 45 lux. The procedure consisted of pre-conditioning (day 1), conditioning (days 2-5), and post-conditioning (day 6). On day 1 (pre-conditioning), mice were i.p. injected with vehicle and initial place preference was determined during $20 \mathrm{~min}$ in order to determine which of the two compartments could be labeled "least preferred" for each mouse. Conditioning (20 min per session) was done using a biased procedure in which amphetamine or cocaine was paired to the least preferred compartment. In this biased procedure, it should be more difficult to obtain a positive CPP response. The mice received a total of two i.p. injections per day where amphetamine or cocaine was administered in the morning and vehicle conditioning in the afternoon, or vice versa. After drug injection, the mice were placed in the appropriate compartment. On day 6 , the mice were placed between the two compartments and were thereafter given free access to both compartments for $20 \mathrm{~min}$. Prior to this test session, the mice were acutely injected with JMV2959 (i.p.) or vehicle. As animals that receive vehicle (in both compartments) are not drug-conditioned, and, therefore, have no drug-induced CPP response to block using an antagonist, such experiments were not conducted. Previ- 
ously, we have shown that JMV2959 has no effect per se on CPP (Jerlhag et al. 2009). CPP was calculated as the difference in percentage of total time spent in the drugpaired (i.e., least preferred) compartment during the postconditioning and the pre-conditioning session.

Radioligand binding assays

In order to study possible affinity of JMV2959 to the dopamine receptors (D1, D2S, and D2L), radioligand binding assays were outsourced to Ricerca Biosciences, LCC (Taipei, Taiwan 112; study no AA94614).

\section{Statistical analyses}

All locomotor activity data were evaluated by a two-way ANOVA followed by Bonferroni post-hoc tests comparing treatments. The microdialysis experiments were evaluated by a two-way ANOVA followed by Bonferroni post-hoc test for comparisons between different treatments and specifically at given time points. The CPP data were evaluated by a one-way ANOVA followed by Bonferroni post-hoc tests comparing treatments. Data are presented as mean \pm SEM. A probability value of $P<0.05$ was considered as statistically significant.

\section{Results}

Effects of a GHS-R1A antagonist on amphetamine-induced locomotor stimulation, accumbal dopamine release and on its ability to condition a place preference in mice

As expected, amphetamine increased locomotor activity, accumbal dopamine release, and induced a CPP. All of these effects of amphetamine were attenuated by peripheral administration of JMV2959 (Figs. 1a, b and 2a). Amphetamine-induced locomotor stimulation $(P<0.001)$ was blocked by a single injection of JMV2959 $(P<0.001)$ in mice $(F(3,28)=14.57, P=0.001)$. Amphetamine increased accumbal dopamine release relative to vehicle treatment $(P=0.001)$, and this effect was attenuated by pre-treatment with JMV2959 $(P=0.01)$ (treatment $F(3,29)=$ 13.31, $P=0.001$; time $F(12,348)=15.98, P=0.001$; treatment $\times$ time interaction $F(12,348)=7.03, P=0.001)$. This difference was evident at time interval of $60 \mathrm{~min}(P<0.01)$. Even though JMV2959 does not completely block the amphetamine-induced dopamine release, this increase fails to reach statistical significance compared to vehicle treatment. The amphetamine-induced CPP was attenuated by an acute single injection of JMV2959 $(F(1,14)=6.82$, $P=0.02$ ).
Effects of a GHS-R1A antagonist on cocaine -induced locomotor stimulation, accumbal dopamine release and on its ability to condition a place preference in mice

In studies parallel to those described for amphetamine, we found that JMV2959 also suppressed the effect of the powerful psychostimulant drug cocaine on activation of the mesolimbic dopamine system (Figs. 1c, d and 2b). Thus, locomotor activity was greatly increased by cocaine administration (relative to vehicle treatment) $(P<0.001)$, and this stimulation was attenuated by JMV2959 pretreatment $(P<0.01)(F(3,28)=28.94, P=0.001)$. JMV2959 does not completely block the cocaine-induced locomotor stimulation compared to vehicle administration $(P<0.001)$. Cocaine increased dopamine release in comparison to vehicle treatment $(P=0.001)$, and this increase was also attenuated by JMV2959 $(P=0.001)$ (treatment $F(3,31)=$ 11.89, $P=0.001$; time $F(12,372)=18.86, P=0.001$; treatment $\times$ time interaction $F(12,372)=10.10, P=0.001)$. This difference was evident at time intervals $20-180 \mathrm{~min}(P<$ 0.01 or $P<0.001)$. Even though JMV2959 does not completely block cocaine-induced accumbal dopamine release, this increase failed to reach statistical significance compared to vehicle treatment. The cocaine-induced CPP was attenuated by an acute single injection of JMV2959 $(F(1,13)=8.22, P=0.01)$.

Control experiments showed that neither i.p. injection, volume infused, nor the GHS-R1A antagonist per se had any effect on locomotor activity (Fig. 1a and c), accumbal dopamine release (Fig. 1b and d), or CPP (Fig. 2a and b).

\section{Probe placements}

After the experiment, the location of the probe was verified and only mice with probe placement in the NAcc were included in the statistical analysis. It should also be emphasized that in a few mice, the probe was located outside the NAcc, and in these mice, no effect of amphetamine/cocaine on accumbal dopamine release was observed (Fig. 3). It should be emphasized that in a few mice, the probe was located outside the NAcc shell, and in these mice, no effect of amphetamine or cocaine on accumbal dopamine release was observed (data not shown). Given that only amphetamine and cocaine increase accumbal dopamine compared to vehicle, it appears less likely that the probes causes structural defects within the NAcc that may influence the possibility to detect dopamine release.

\section{Radioligand binding}

The radioligand binding studies show that JMV2959 does not bind to human dopamine D1, D2L, and D2S 
a
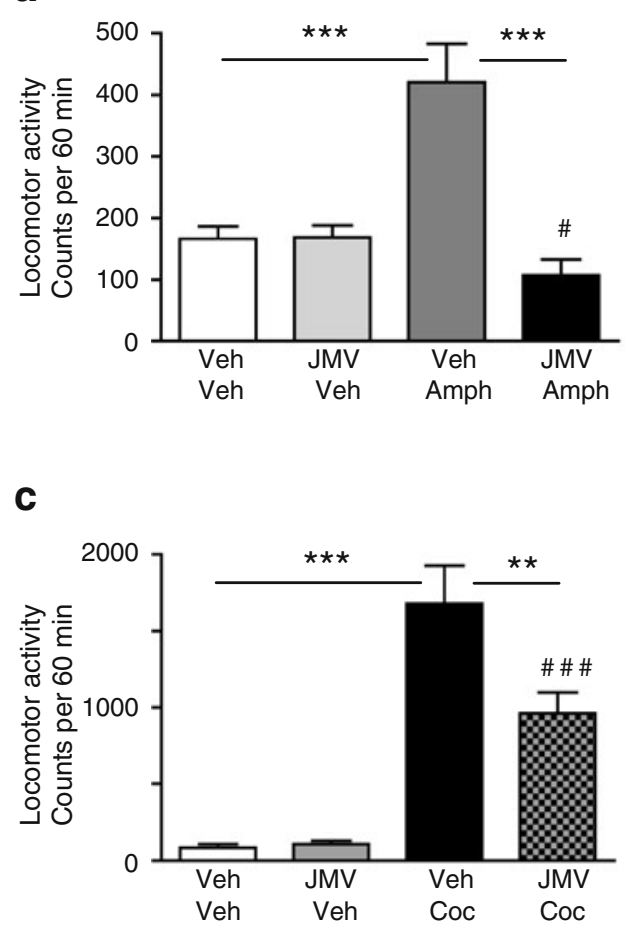

Fig. 1 Suppressed ghrelin signaling by ghrelin receptor (GHS-R1A) antagonist (JMV2959) attenuates amphetamine, and cocaine-induced locomotor stimulation and accumbal dopamine release. a Amphetamineinduced locomotor stimulation was attenuated by a single i.p. injection of JMV2959, but not by vehicle injection in mice $(n=8$ in each group; ${ }^{* * *} P<0.001,{ }^{\#} P=$ n.s for Veh-Veh vs JMV-Amph). b The amphetamine-induced increase in accumbal dopamine release was absent in GHS-R1A antagonist (JMV2959, i.p.), but not in vehicletreated mice ( $n=8$ in Veh-Veh (square), Veh-Amph (filled triangle), and JMV-Veh (triangle) groups and $n=9$ in JMV-Amph (circle) group). This difference was evident at time interval $60 \mathrm{~min}\left({ }^{* *} P<0.01\right.$, Bonferroni post-hoc test). Even though JMV2959 does not completely block the amphetamine-induced accumbal dopamine release, this increase fails to
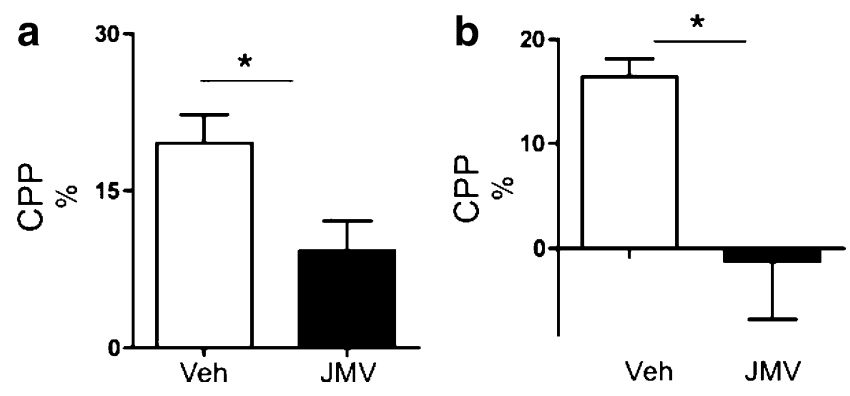

Fig. 2 The ghrelin receptor (GHS-R1A) antagonist (JMV2959) attenuates amphetamine- and cocaine-induced conditioned place preference (CPP). a The amphetamine-induced CPP $(n=8)$ was attenuated by an acute single i.p. injection of the GHS-R1A antagonist, JMV2959 $(n=8)$, in mice. b A cocaine-induced CPP in mice pre-treated with vehicle $(n=7)$ was obtained, and pre-treatment with JMV2959 $(n=8)$ attenuated this stimulation in mice $(* P<0.05)$. All values represent mean \pm SEM
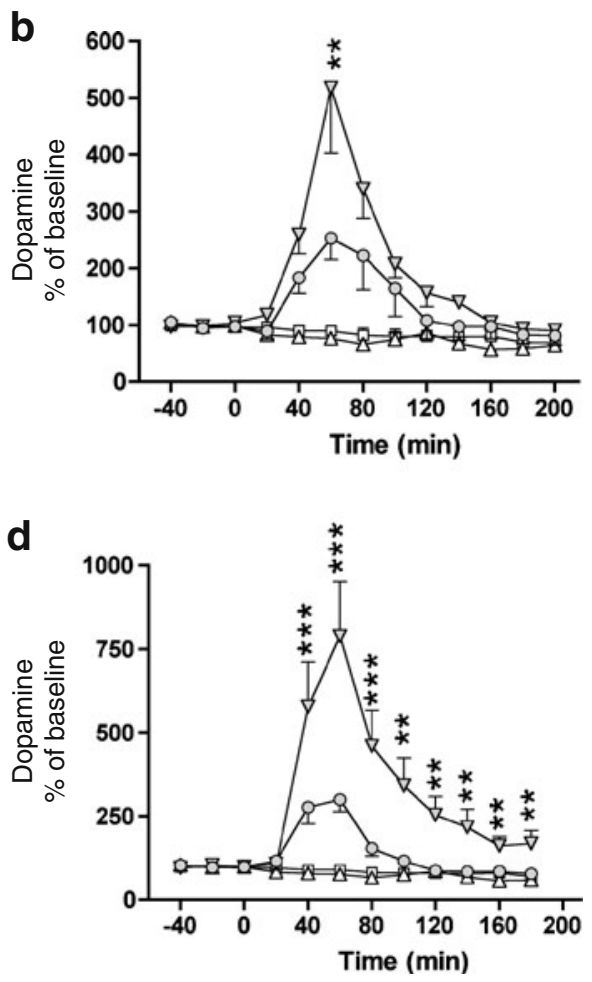

reach statistical significance compared to vehicle treatment. c Cocaineinduced locomotor stimulation was attenuated by a single i.p. injection of JMV2959, but not by vehicle injection in mice ( $n=8$ in each group). (**P<0.01, ${ }^{* * *} P<0.001,{ }^{\# \#} P<0.001$ for Veh-Veh vs JMV-Coc). $\mathbf{d}$ The cocaine-induced increase in accumbal dopamine release was absent in GHS-R1A antagonist (JMV2959, i.p.), but not in vehicle-treated mice ( $n=8$ in Veh-Veh (square) and JMV-Veh (triangle) groups, $n=9$ in VehCoc (filled triangle) and $n=10$ in JMV-Coc groups (circle). This difference was evident at time intervals $20-180 \mathrm{~min}\left(* * P<0.01,{ }^{* * *} P<\right.$ 0.001). Even though JMV2959 does not completely block the cocaineinduced accumbal dopamine release, this increase fails to reach statistical significance compared to vehicle treatment

receptors up to a concentration of $10 \mu \mathrm{M}$, whereas JMV2959 does bind to the human GHS-R1A with an IC50 of $32 \mathrm{nM}$ (Moulin et al. 2007). These data support the specificity of JMV2959 as a selective GHS-R1A antagonist.

\section{Discussion}

The present study demonstrates that the ghrelin signaling system, involving GHS-R1A, is required for indirect measures of the rewarding properties of the psychostimulant drugs, amphetamine and cocaine. Hence, we found that the ability of these drugs to induce locomotor stimulation, accumbal dopamine release, and to condition a place preference is reduced in mice treated peripherally with a GHS-R1A antagonist. These effects of drugs of abuse, considered to constitute part of the addiction process, are 
Fig. 3 Verification of probe placement. A coronal mouse brain section showing ten representative probe placements (vertical lines) in the NAcc of mice used in the present study (Franklin and Paxinos 1996). Ten representative placements are illustrated, but all other placements were within the NAcc shell. The probe is not shown to scale, and the outer diameter of the probe was $310 \mu \mathrm{m}$. Placements outside this area were not included in the statistical analysis. The number given in the brain section indicates millimeters anterior $(+)$ from bregma

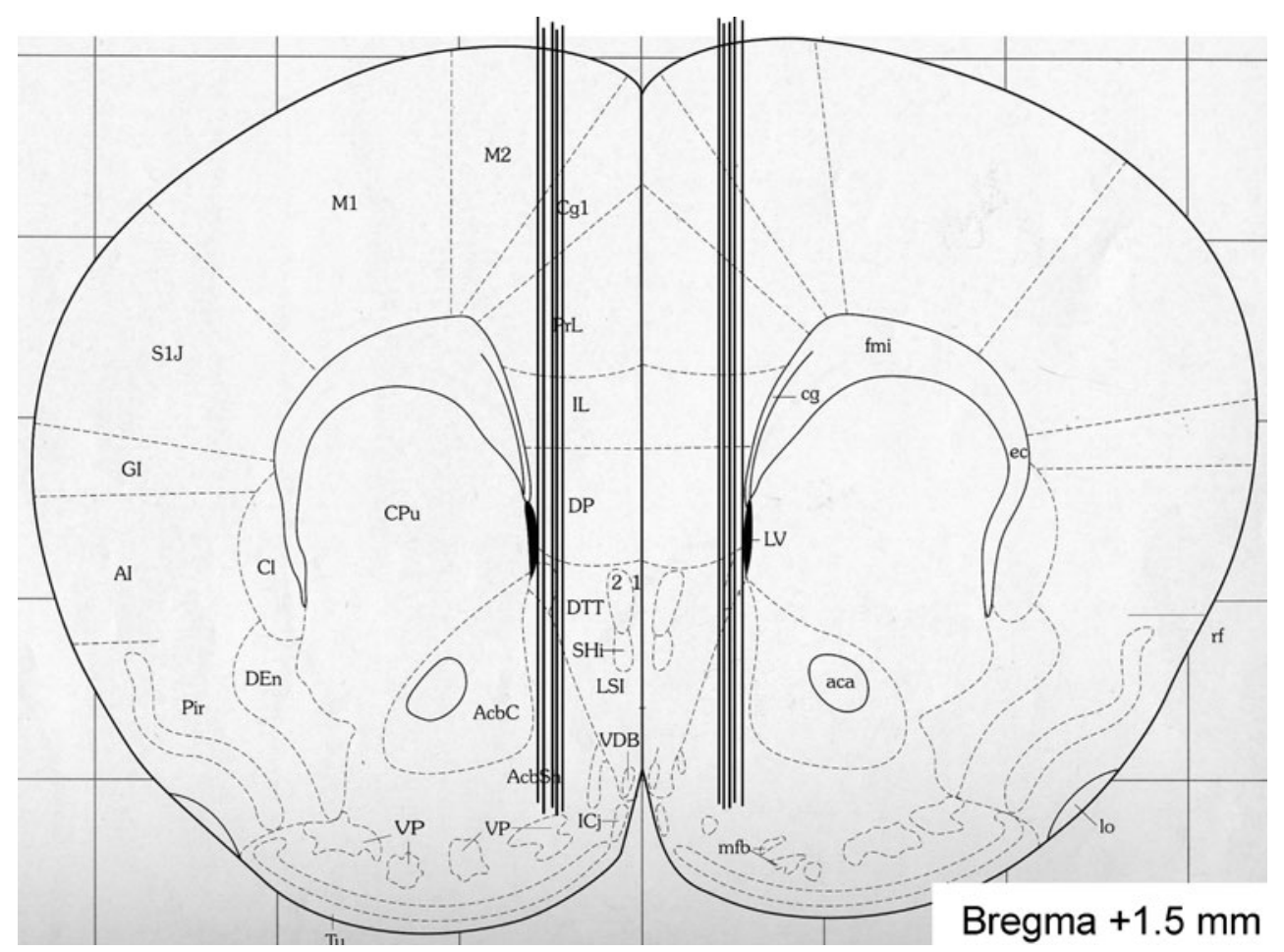

intimately associated with its reinforcing properties (Wise and Bozarth 1987). The GHS-R1A was administered peripherally in the present study, but it seems likely that it gains access to the CNS and acts at the level of the mesolimbic dopamine system (Jerlhag et al. 2009). Taken together with our recent studies showing that the central ghrelin signaling system is required for alcohol- induced locomotor stimulation, accumbal dopamine release, and CPP (Jerlhag et al. 2009), these data support the idea that GHS-R1A may play an important role in addiction processes.

Supporting a role of ghrelin signaling in drug reinforcement are data demonstrating that food restriction, a state which is associated with elevated ghrelin levels, augments cocaine, as well as amphetamine-induced locomotor stimulation facilitates the acquisition of cocaine-seeking behavior and enhances self-administration of cocaine or amphetamine in rats (Carroll et al. 1979; Carroll and Stotz 1983; Bell et al. 1997; Carr 2002; Gualillo et al. 2002). However, a role of stress should not be excluded. Moreover, in rats, an elevated plasma level of ghrelin enhances cocaine-seeking and augments cocaine-induced reward, assessed by locomotor stimulation, as well as CPP testing (Wellman et al. 2005; Davis et al. 2007; Tessari et al. 2007). The finding that GHS-R1A is constitutively active in the absence of ligand (Holst et al. 2003) makes it difficult to determine to what extent drug-induced reward is dependent on signaling by endogenous ghrelin, or by the activity of the GHS-R1A per se.
The ability of psychostimulant drugs to activate the mesolimbic dopamine system and thereby cause reinforcement may be due to increased dopamine synthesis, increased dopamine release, and/or enhanced activity of the mesolimbic dopamine neurons. Neurotransmitters in areas such as the NAcc and the ventral tegmental area (VTA) collectively regulate this activation (Samson et al. 1991; White et al. 1995; Reith et al. 1997; Zhang et al. 1997). Here it was shown that GHS-R1A, possibly at the level of the mesolimbic dopamine system, mediates the stimulatory, dopamine releasing, and CPP properties of psychostimulant drugs. In the VTA, GHS-R1A is expressed on dopaminergic neurons (Abizaid et al. 2006), and it has been suggested that GHS-R1A regulates the activity of tegmental dopamine neurons via heterodimeraziation of the GHS-R1A to the dopamine D1 receptor, as well as by the constitutive activity of the GHS-R1A (Holst et al. 2003; Jiang et al. 2006). By this route, GHS-R1A may modulate the ability and sensitivity of the mesolimbic dopamine neurons to be activated by psychostimulant drugs. The possibility that GHS-R1A influences the synthesis and release of dopamine should also be considered. In the NAcc, the dopamine released by amphetamine and cocaine activates dopamine receptors, and it should therefore be considered that the GHS-R1A antagonist attenuates psychostimulant-induced reinforcement by inhibiting the dopamine receptors in the NAcc. This appears less likely since JMV2959 did not bind to any of the dopamine receptors (D1, D2L and D2S) in concentrations up to 
$10 \mu \mathrm{M}$, whereas it binds to the GHS-R1A with an IC50 of $32 \mathrm{nM}$ (Moulin et al. 2007). GHS-R1A in the NAcc may also be of importance for psychostimulant-induced locomotor stimulation, dopamine release, and CPP even though they do not appear to regulate alcohol consumption (Schneider et al. 2007). Thus, it should be considered that the GHS-R1A antagonist might reduce the psychostimulantinduced reward via interruption of the reported heterodimeraziation of the GHS-R1A to the dopamine D1 receptor (Jiang et al. 2006). The possibility remains, however, that downstream mechanisms independent of the mesolimbic dopamine system also may have important roles for the rewarding properties of cocaine and amphetamine.

Our collective findings regarding the role of the central ghrelin signaling system, including the GHS-R1A, in alcohol (Jerlhag et al. 2009), as well as amphetamine- and cocaine-induced rewards may also have clinical relevance since hyperghrelinemia is found in individuals with substance use disorder, for example, after methamphetamine use and in alcohol-use disorder, specifically in those with high craving scores (Kim et al. 2005; Kraus et al. 2005; Addolorato et al. 2006; Hillemacher et al. 2007; Kobeissy et al. 2008). Furthermore, one study has demonstrated that a single-nucleotide polymorphism in the GHSR1A gene is associated with high alcohol consumption (Landgren et al. 2008). Collectively, these findings rise important questions regarding the physiological role of ghrelin influencing not only food intake and appetite, but also clearly having a broader role in reward induced by addictive drugs such as alcohol, amphetamine, and cocaine. Our data suggest that the central ghrelin signaling system, including the GHS-R1A, constitutes a novel potential target for treatment of addictive behaviors such as drug dependence.

Acknowledgements The authors are grateful for the excellent help of Mrs. Gun Andersson and Mr. Kenn Johannessen. The GHS-R1A antagonist JMV2959 was supplied by Æterna Zentaris under a material transfer agreement. Prof. Jean Martinez and Dr. Jean-Alain Fehrentz are acknowledged for the synthesis of JMV2959. Supported by the Swedish Research Council (K2006-21X-04247-33-3 \& K200754X-20328-013), the Alcohol Research Council of the Swedish Alcohol Retailing Monopoly, The Swedish Labour Market Insurance, The Swedish Brain Foundation, Swedish Council for Tobacco Research, the foundations of Wilhelm and Martina Lundgren, Knut and Alice Wallenberg, The Adlerbert Research, Thuring's, Längmanska art, Torsten and Ragnar Söderberg, Magnus Bergvall foundation, European Union (FP7-HEALTH-2009-241592; FP7-KBBE-2009245009), Novo Nordisk (GeA/AIR), ALF Göteborg (SU7601, SU76540), the Swedish Foundation for Strategic Research to Sahlgrenska Center for Cardiovascular and Metabolic Research (A305-188), and The Swedish Society of Medicine.

Open Access This article is distributed under the terms of the Creative Commons Attribution Noncommercial License which permits any noncommercial use, distribution, and reproduction in any medium, provided the original author(s) and source are credited.

\section{References}

Abizaid A, Liu ZW, Andrews ZB, Shanabrough M, Borok E, Elsworth JD, Roth RH, Sleeman MW, Picciotto MR, Tschöp MH, Gao XB, Horvath TL (2006) Ghrelin modulates the activity and synaptic input organization of midbrain dopamine neurons while promoting appetite. J Clin Invest 116:3229-3239

Addolorato G, Capristo E, Leggio L, Ferrulli A, Abenavoli L, Malandrino N, Farnetti S, Domenicali M, D'Angelo C, Vonghia L, Mirijello A, Cardone S, Gasbarrini G (2006) Relationship between ghrelin levels, alcohol craving, and nutritional status in current alcoholic patients. Alcohol Clin Exp Res 30:1933-1937

Bell SM, Stewart RB, Thomson SC, Meisch RA (1997) Fooddeprivation increases cocaine-induced conditioned place preference and locomotor activity in rats. Psychopharmacology $131: 1-8$

Blomqvist O, Engel JA, Nissbrandt H, Söderpalm B (1993) The mesolimbic dopamine-activating properties of ethanol are antagonized by mecamylamine. Eur J Phamacol 249:207-213

Carr KD (2002) Augmentation of drug reward by chronic food restriction: behavioral evidence and underlying mechanisms. Physiol Behav 76:353

Carroll ME, Stotz DC (1983) Oral d-amphetamine and ketamine selfadministration by rhesus monkeys: effects of food deprivation. J Pharmacol Exp Ther 227(1):28-34

Carroll ME, France CP, Meisch RA (1979) Food deprivation increases oral and intravenous drug intake in rats. Science 205:319-321

Davis KW, Wellman PJ, Clifford PS (2007) Augmented cocaine conditioned place preference in rats pretreated with systemic ghrelin. Regul Pept 140:148-152

Dickson SL, Luckman SM (1997) Induction of c-fos messenger ribonucleic acid in neuropeptide $\mathrm{Y}$ and growth hormone (GH)releasing factor neurons in the rat arcuate nucleus following systemic injection of the GH secretagogue, GH-releasing peptide-6. Endocrinology 138:771-777

Engel JA, Fahlke C, Hulthe P, Hård E, Johannessen K, Snape B, Svensson L (1988) Biochemical and behavioral evidence for an interaction between ethanol and calcium channel antagonists. J Neural Transm 74:181-193

Engel JA, Falkhe C, Hård E, Johannessen K, Svensson L, Söderpalm B (1992) Serotonergic and dopaminergic involvement in ethanol intake. Clin Neuropharmacol 15:64A-65A

Franklin KBJ, Paxinos G (1996) The mouse brain in stereotaxic coordinates. Academic, New York

Gualillo O, Caminos JE, Nogueiras R, Seoane LM, Arvat E, Ghigo E, Casanueva FF, Dieguez C (2002) Effects of food restriction on ghrelin in normal-cycling female rats and in pregnancy. Obes Res 10(7):682-687

Hewson AK, Tung LY, Connell DW, Tookman L, Dickson SL (2002) The rat arcuate nucleus integrates peripheral signals provided by leptin, insulin, and a ghrelin mimetic. Diabetes 51:3412-3419

Hillemacher T, Kraus T, Rauh J, Weiss J, Schanze A, Frieling H, Wilhelm J, Heberlein A, Groschl M, Sperling W, Kornhuber J, Bleich S (2007) Role of appetite-regulating peptides in alcohol craving: an analysis in respect to subtypes and different consumption patterns in alcoholism. Alcohol Clin Exp Res 31:950-954

Holst B, Cygankiewicz A, Jensen TH, Ankersen M, Schwartz TW (2003) High constitutive signaling of the ghrelin receptor-identification of a potent inverse agonist. Mol Endocrinol 17:2201-2210

Imperato A, Di Chiara G (1986) Preferential stimulation of dopamine release in the nucleus accumbens of freely moving rats by ethanol. J Pharmacol Exp Ther 239:219-228

Jerlhag E (2008) Systemic administration of ghrelin induces conditioned place preference and stimulates accumbal dopamine. Addict Biol 13:358-363 
Jerlhag E, Egecioglu E, Dickson SL, Andersson M, Svensson L, Engel JA (2006) Ghrelin stimulates locomotor activity and accumbal dopamine overflow via central cholinergic mechanisms: implications for its involvement in brain reward. Addict Biol 11:45-54

Jerlhag E, Egecioglu E, Dickson SL, Douhan A, Svensson L, Engel JA (2007) Ghrelin administration into tegmental areas ghrelin administration stimulates locomotor activity and increases extracellular concentration of dopamine in the nucleus accumbens. Addict Biol 12:6-16

Jerlhag E, Egecioglu E, Dickson SL, Svensson L, Engel JA (2008) Alphaconotoxin MII-sensitive nicotinic acetylcholine receptors are involved in mediating locomotor stimulatory and dopamine enhancing properties of ghrelin. Eur Neuropsychopharmacol 18:508-518

Jerlhag E, Egecioglu E, Landgren S, Salomé N, Heilig M, Moechars D, Perissoud D, Dickson SL, Engel JA (2009) Requirement of central ghrelin signaling for alcohol reward. PNAS 106:11318-11323

Jiang H, Betancourt L, Smith RG (2006) Ghrelin amplifies dopamine signaling by cross talk involving formation of growth hormone secretagogue receptor/dopamine receptor subtype 1 heterodimers. Mol Endocrinol 20:1772-1785

Keen-Rhinehart E, Bartness TJ (2004) Peripheral ghrelin injections stimulate food intake, foraging and food hoarding in Seberian hamster. Am J Physiol Regul Integr Comp Physiol 288:R716-R722

Kim DJ, Yoon SJ, Choi B, Kim TS, Woo YS, Kim W, Myrick H, Peterson BS, Choi YB, Kim YK, Jeong J (2005) Increased fasting plasma ghrelin levels during alcohol abstinence. Alcohol Alcohol 40(1):76-79

Kobeissy FH, Jeung JA, Warren MW, Geier JE, Gold MS (2008) Changes in leptin, ghrelin, growth hormone and neuropeptide-Y after an acute model of MDMA and methamphetamine exposure in rats. Addict Biol 13:15-25

Kojima M, Hosoda H, Date Y, Nakazato M, Matsuo H, Kangawa K (1999) Ghrelin is a growth-hormone-releasing acylated peptide from stomach. Nature 402:656-660

Kraus T, Schanze A, Groschl M, Bayerlein K, Hillemacher T, Reulbach U, Kornhuber J, Bleich S (2005) Ghrelin levels are increased in alcoholism. Alcohol Clin Exp Res 12:2154-2157

Landgren S, Jerlhag E, Zetterberg H, Gonzàlez-Quintela A, Olofsson U, Nilsson S, Blennow K, Engel JA (2008) Association of pro-ghrelin and GHS-R1A polymorphisms and haplotypes with heavy alcoholuse and body-mass. Alcohol Clin Exp Res 32:2054-2061

Malik S, McGlone F, Bedrossian D, Dagher A (2008) Ghrelin modulates brain activity in areas that control appetitive behavior. Cell Metab 7:400-409

Moulin A, Demange L, Berge G, Gagne D, Ryan J et al (2007) Toward potent ghrelin receptor ligands based on trisubstituted 1 ,
2, 4-triazole structure. 2. Synthesis and pharmacological in vitro and in vivo evaluations. J Med Chem 50:5790-5806

Nogueiras R, Perez-Tilve D, Wortley KE, Tschöp M (2006) Growth hormone secretagogue (ghrelin-) receptors - a complex drug target for the regulation of body weight. CNS Neurol Disord Drug Targets 5:335-343

Reith ME, Li MY, Yan QS (1997) Extracellular dopamine, norepinephrine, and serotonin in the ventral tegmental area and nucleus accumbens of freely moving rats during intracerebral dialysis following systemic administration of cocaine and other uptake blockers. Psychopharmacology (Berl) 134:309-317

Salomé N, Haage D, Perrissoud D, Moulin A, Demange L, Egecioglu E, Fehrentz J-A, Martinez J, Dickson SL (2009) Anorexigenic and electrophysiological actions of novel ghrelin receptor (GHSR1A) antagonists in rats. Eur J Pharmacol 612:167-173

Samson HH, Tolliver GA, Haraguchi M, Kalivas PW (1991) Effects of D-amphetamine injected into the n.accumbens on ethanol reinforced behavior. Brain Res Bull 27:267-271

Sanchis-Segura C, Spanagel R (2006) Behavioural assessment of drug reinforcement and addictive features in rodents: an overview. Addict Biol 11:2-38

Schneider ER, Rada P, Darby RD, Leibowitz SF, Hoebel BG (2007) Orexigenic peptides and alcohol intake: differential effects of orexin, galanin, and ghrelin. Alcohol Clin Exp Res 31:18581865

Tessari M, Catalano A, Pellitteri M, Di Francesco C, Marini F, Gerrard PA, Heidbreder CA, Melotto S (2007) Correlation between serum ghrelin levels and cocaine-seeking behaviour triggered by cocaine associated conditioned stimulus in rats. Addict Biol $12: 22-29$

Wellman PJ, Davis KW, Nation JR (2005) Augmentation of cocaine hyperactivity in rats by systemic ghrelin. Regul Pept 125:151154

Westerink BHC (1995) Brain microdialysis and its applications for the study of animal behaviour. Behav Brain Res 70:103-124

White FJ, Hu XT, Zhang XF, Wolf ME (1995) Repeated administration of cocaine or amphetamine alters neuronal responses to glutamate in the mesoaccumbens dopamine system. J Pharmacol Exp Ther 273:445-454

Wise RA, Bozarth MA (1987) A psychomotor stimulant theory of addiction. Psychol Rev 94(4):469-492

Zhang XF, Hu XT, White FJ, Wolf ME (1997) Increased responsiveness of ventral tegmental area dopamine neurons to glutamate after repeated administration of cocaine or amphetamine is transient and selectively involves AMPA receptors. J Pharmacol Exp Ther 281:699-706 